\title{
Determinants of acute hospital care use by elderly patients in Italy from 1996 to 2006
}

\author{
Giuseppe Liotta, Sandro Mancinelli, Paola Scarcella, Leonardo Emberti Gialloreti * \\ Department of Public Health and Cell Biology, University of Rome "Tor Vergata", via Montpellier 1, 00133 Rome, Italy
}

\section{A R T I C L E I N F O}

\section{Article history:}

Received 28 February 2011

Received in revised form 29 July 2011

Accepted 1 August 2011

Available online 6 September 2011

\section{Keywords:}

Older patients

Hospital admission

Hospital stay

Home care

Multivariate linear regression models

\begin{abstract}
A B S T R A C T
To determine the trend of elderly hospitalization rates in Italy, following the economic rationalization of health systems in Western countries, and to evaluate which alternatives to acute hospitalization have been developed during the period 1996-2006 an ecological observational study has been carried out. Data from the Italian Hospital-Discharge Registries (HDRs) of the years 1996, 2001, and 2006 have been analyzed in order to assess the variations among the elderly in terms of hospitalization rates, hospital stay, and bed rates. The results were compared with nursing home admission rates and home care offer. Relations among these variables were explored by univariate and multivariate analyses. Elderly hospital admission rates decreased in Italy from 324.2/1000 in 1996, to 258.7 in 2006. Mean hospital stay of elderly patients was 9.4 days in 2006, 9.5 in 2001 and 10.1 in 1996. A multivariate linear regression model was statistically significant in explaining the variations in hospitalization rates $(F: 5.68 ; p=0.004$; $\left.R^{2}=0.77\right)$. The main determinants linked to such variations were the bed rate $(\beta=0.67 ; p=0.004)$ and the hospital length of stay $(\beta=-0.77 ; p=0.03)$. The analysis showed a reduction in hospitalization rates among the elderly, which was not counterbalanced by an increased offer of home care and/or nursing home services, but was mainly linked to a decrease in the supply of acute beds, with possible consequences on the quality of health care.
\end{abstract}

(c) 2011 Elsevier Ireland Ltd. All rights reserved.

\section{Introduction}

Hospital services are the most expensive component of Western health systems. Therefore, actions in the direction of economic rationalization have put pressure on acute hospital facilities to decrease length of stay and to reduce the number of acute beds (Reinhardt, 1996; Department of Health, 2002). While inpatient beds have been reduced in almost every country, several strategies to shift care out of hospital into the community sectors have been developed (Shepperd et al., 2009). Alternatives to inpatient care have become a focus of interest among health service providers, as they seem to offer potential for reducing both hospital admissions and stay (Coast et al., 1996).

Also the Italian Health System is trying to improve the efficiency of health services by reducing the number of available beds in hospitals and by trying to use the remaining beds as efficiently as possible, avoiding inappropriate hospital stay (Istituto Nazionale di Statistica, 2003). The introduction, in 1996, of Diagnosis-Related Groups (DRGs) provided in Italy an incentive for rapid discharge (Jommi et al., 2001), calling for the need to develop a continuity of care between health-care settings.

\footnotetext{
* Corresponding author. Tel.: +39 0672596613, fax: +390620427263.

E-mail address: leonardo.emberti.gialloreti@uniroma2.it (L. Emberti Gialloreti).
}

In Italy, this should be coordinated by the Local Health Units, public schemes that depend upon the Italian regions and have administrative independence (France et al., 2005). In fact, the Italian Ministry of Health approved, already in 1992, the "Obiettivo Anziani" ("Focus on Elderly") Document, which foresaw the implementation of the continuity of care (France et al., 2005).

Reductions in hospital stay have occurred during the past 20 years in the majority of Western countries (Merriman, 2008). However, such focus on cost containment by reducing acute bed availability is taking place in the wider context of aging populations. The characteristics of the conditions linked to aging are such that they often increase demand for acute beds and for prolonged hospital stay (Audit Commission, 1997). In fact, elderly patients represent a large number of hospital admissions (Dainty and Elizabeth, 2009), consuming a substantial share of hospital resources (Preyde et al., 2009). This is one of the reasons why an aging population, together with the increasing cost of medical technologies, has been indicated as a major cause of the increase in expenditures (Seshamani and Gray, 2002; Liotta and Brenna, 2007).

Reducing hospital stay of older patients might have led in some cases to reductions in quality of life (Graves, 1995) or nursing home placement (Oddone et al., 1996). To minimize these effects, while reducing at the same time pressure on acute hospitals, one proposed alternative has been an increased offer of community 
services. One consequence has been, in some Western countries, a remarkable growth in home care services (Stuart and Weinrich, 2001; Preyde et al., 2009), the development of hospital discharge programs (Jack et al., 2009a), and experimentations of "hospital at home" services (Coast et al., 1998).

At present, in Italy no data are available about trends of hospitalization rates among the elderly in relation to nursing homes and community care places. This paper thus aims at identifying if such a relation exists, by pooling data from different sources. For this reason we examined the hospitalization trends of the elderly population in Italy during a ten-year long period and compared data of the years 1996, 2001 and 2006, retrieved from the HDRs, in order to analyze the qualitative and quantitative variations among the elderly in terms of hospitalization rates, length of hospital stay, hospital bed rates, as well as possible determinants of these variations.

\section{Methods}

\subsection{Study design and data sources}

In this population-based ecological study, we analyzed the aggregated data of the Italian HDRs of the years 1996, 2001, and 2006, focusing on persons older than 65 years. We excluded hospitalizations that lasted $\leq 1$ day, as such cases are mainly emergency-ward accesses, which did not imply a hospitalization and whose admission reasons cannot be clearly delineated.

The 21 existing HDRs cover all hospitalizations in acute hospitals funded by the Public National Health System (NHS). The Ministry of Health combines the 21 HDRs in one single database, which, therefore, covers the whole Italian territory. This means that discharge-data of all public hospitals and private hospitals funded by the NHS can be retrieved from this database. The HDRs, established for the first time in 1995, use a standard discharge form (SDO) to document patients' demographic and health data. The SDO registers all hospital discharges, since SDO data, from 1996 on, contribute to the determination of the appropriate DRG. The SDO data are recorded with the consent of the patient, and can be used as aggregated data for scientific studies without further authorizations.

Number of nursing homes and number of subjects receiving home-care services were retrieved from registries available in the different Italian regions. As no single national registry exists in Italy, we had to take into account the different definitions of nursing homes or home-care services used by the various regions.

Population sizes were obtained from the Italian National Institute of Statistics (ISTAT) website (Istituto Nazionale di Statistica, 2010). Hospitalization rates, beds per 1000 inhabitants, number of nursing home beds, and number of home care patients per 1000 inhabitants were calculated in relation to the resident population in each Italian region, with figures obtained for the years 1996, 2001 and 2006 from the ISTAT website.

\subsection{Statistical analysis}

Variables were compared in bivariate analyses using the $t$-test, the Fisher exact test, or the Pearson correlation, as appropriate. To explore the question of what factors were associated with hospitalization rates and length-of-stay variations, univariate and multivariate linear regressions were used to determine whether there were independent relationships among the variables. We used 2-sided significance tests, considering P values less than 0.05 to be statistically significant. All data were analyzed with SPSS, version 16.0.

\section{Results}

\subsection{Hospital admissions of the elderly}

During the year 2006 the HDRs registered 2,999,617 hospital admissions of elderly people, with a $5.90 \%$ decrease in comparison with 2001 (Table 1). In 2001 the admissions had already increased by $1.95 \%$ compared with 1996 . However, in the same period the overall elderly population of Italy increased from 9,602,356 in 1996 , to $11,592,966$ in 2006 , i.e. a $20.7 \%$ increase. As a result, the elderly hospital admission rates decreased from 324.2/1000 elderly people in 1996, to 302.1 in 2001 and 258.7 in 2006 (Table 1 ), accounting for an overall decrease of $20.2 \%$. In the five-year period 1996-2001, admission rates decreased by $6.8 \%$, while in the period 2001-2006 we observed a $14.3 \%$ reduction. In the period 2001-2006 the decline in admission rates concerned both the elderly aged $65-74$ years (247.7/1000 in 2001 vs. 208.7 in 2006; $-15.7 \%)$, and those older than 74 (371.3/1000 in 2001 vs. 316.0 in 2006; -14.9\%).

In the same period, a similar drop in hospitalization rates ( $-16.1 \%$ ) could be observed also among the adults (15-64 years).

Hospitalization rates in 2006 varied remarkably among the different Italian regions, ranging from 193.1/1000 $\geq 65$ inhabitants in Piemonte to 359.5/1000 in Molise. The overall rate for Italy was 258.7/1000 (Table 2). Between 2001 and 2006, hospitalization rates decreased in all regions, varying from a 3.96\% (Molise) to a 22.96\% (Marche) decrease.

\subsection{Hospital bed rates and length of stay}

The overall bed rate in 2006 in Italy was 4.7/1000 inhabitants, ranging from 3.6/1000 in Campania to 5.8/1000 in Lazio (Table 2). Between 2001 and 2006 the bed rates decreased in all but one (Molise; $0.60 \%$ increase) Italian regions, ranging from a $0.10 \%$ (Sicilia) to a $1.70 \%$ (Puglia) decrease.

Table 1

Elderly hospital admissions: Absolute numbers, rates, change $(\Delta)$, and percentage of change, compared to the previous year (1996-2006).

\begin{tabular}{|c|c|c|c|c|}
\hline & Year & & $\Delta$ & Percentage of $\Delta$ \\
\hline \multirow[t]{3}{*}{ Elderly admissions (without Sicily ${ }^{\mathrm{a}}$ ) } & 1996 & $2,878,900$ & & \\
\hline & 2001 & $2,934,985$ & $+56,085$ & $+1.95 \%$ \\
\hline & 2006 & $2,744,834$ & $-190,151$ & $-6.48 \%$ \\
\hline \multirow{2}{*}{ Elderly admissions (all Italian regions) } & 2001 & $3,189,520$ & & \\
\hline & 2006 & $2,999,617$ & $-189,903$ & $-5.90 \%$ \\
\hline \multirow[t]{3}{*}{ Elderly admission rate per 1000 inhabitants } & 1996 & 324.2 & & \\
\hline & 2001 & 302.1 & -22.1 & $-6.80 \%$ \\
\hline & 2006 & 258.7 & -43.4 & $-14.30 \%$ \\
\hline \multirow[t]{3}{*}{ Elderly population (absolute numbers) } & 1996 & $9,602,356$ & & \\
\hline & 2001 & $10,654,649$ & $+1,052,293$ & $+11.0 \%$ \\
\hline & 2006 & $11,592,966$ & $+938,317$ & $+8.80 \%$ \\
\hline
\end{tabular}

\footnotetext{
${ }^{a}$ In 1996 data for Sicily were not available.
} 
Table 2

Baseline parameters in the different Italian administrative regions.

\begin{tabular}{|c|c|c|c|c|c|c|c|c|}
\hline Region & $\begin{array}{l}\geq 65 \text { Hospitalization } \\
\text { rate per } 1000 \geq 65 \\
\text { inhabitants }\end{array}$ & $\begin{array}{l}\geq 65 \text { average } \\
\text { length of } \\
\text { stay (days) }\end{array}$ & $\begin{array}{l}\text { Beds per } \\
1000 \\
\text { inhabitants }\end{array}$ & $\begin{array}{l}\text { Percentage } \\
\text { of private } \\
\text { beds out } \\
\text { of the total } \\
\text { number of beds } \\
\text { (private and } \\
\text { public) }\end{array}$ & $\begin{array}{l}\geq 65 \text { outpatients } \\
\text { admissions/total } \\
\geq 65 \text { admission rate }\end{array}$ & $\begin{array}{l}\text { Institutionalization } \\
\text { rate }^{\mathrm{a}}\end{array}$ & $\begin{array}{l}\text { Number of } \geq 65 \\
\text { Home Care patients } \\
\text { per } 1000 \geq 65 \\
\text { inhabitants }\end{array}$ & $\begin{array}{l}\text { Percentage } \\
\text { of elderly out } \\
\text { of the total } \\
\text { population }\end{array}$ \\
\hline Abruzzo & 344.2 & 8.1 & 5.1 & 28 & 21.10 & 15.08 & 36.6 & 21.28 \\
\hline Basilicata & 252.4 & 8.9 & 4.3 & 3 & 29.80 & 4.73 & 40.9 & 19.93 \\
\hline Calabria & 262.6 & 8.8 & 4.6 & 50 & 23.10 & 4,88 & 11.6 & 18.27 \\
\hline Campania & 266.7 & 8.0 & 3.6 & 53 & 25.50 & 4.73 & 12.4 & 15.33 \\
\hline Emilia $\mathrm{R}$ & 250.8 & 9.1 & 5.2 & 28 & 19.30 & 25.14 & 49.9 & 22.80 \\
\hline Friuli & 252.7 & 10.5 & 4.8 & 15 & 14.30 & 36.06 & 77.8 & 22.58 \\
\hline Lazio & 289.0 & 10.1 & 5.8 & 49 & 26.90 & 13.83 & 39.2 & 19.12 \\
\hline Liguria & 228.7 & 10.3 & 4.4 & 1 & 32.20 & 25.95 & 11.8 & 26.64 \\
\hline Lombardia & 249.7 & 9.6 & 4.9 & 29 & 29.00 & 26.58 & 35.2 & 19.50 \\
\hline Marche & 239.9 & 9.8 & 4.6 & 20 & 26.00 & 19.11 & 26.8 & 22.57 \\
\hline Molise & 359.5 & 9.1 & 5.7 & 14 & 23.70 & 15.16 & 67.8 & 21.99 \\
\hline PA Bolzano & 355.4 & 9.5 & 5.1 & 17 & 21.90 & n.a & 2.5 & 17.57 \\
\hline PA Trento & 240.3 & 10.9 & 5.0 & n.a. & 26.50 & 49.93 & n.a. & 17.51 \\
\hline Piemonte & 193.1 & 11.0 & 3.8 & 28 & 34.40 & 38.15 & 18.6 & 22.56 \\
\hline Puglia & 305.0 & 8.7 & 4.0 & 14 & 20.50 & 7.74 & 12.6 & 17.29 \\
\hline Sardegna & 280.6 & 9.3 & 4.9 & 26 & 23.30 & 14.04 & 7.3 & 17.61 \\
\hline Sicilia & 282.5 & 7.7 & 4.3 & 31 & 36.00 & 6.79 & 7.9 & 17.97 \\
\hline Toscana & 237.3 & 9.2 & 4.5 & 16 & 21.00 & 14.82 & 28.1 & 23.29 \\
\hline Umbria & 230.5 & 8.6 & 4.2 & 7 & 26.30 & 11.13 & 24.8 & 23.33 \\
\hline Val d'Aosta & 226.4 & 12.5 & 4.0 & 0 & 27.70 & 38.55 & 2.0 & 20.20 \\
\hline Veneto & 256.8 & 10.6 & 4.5 & 6 & 23.70 & 34.17 & 43.7 & 19.21 \\
\hline Italia & 258.74 & 9.4 & 4.7 & 26 & 26.00 & 19.88 & 30.3 & 19.77 \\
\hline
\end{tabular}

n.a. - Not available.

a Elderly admitted in Nursing Homes/elderly population.

On the whole, $26 \%$ of acute hospital beds were in private hospitals funded by the NHS. The remaining $74 \%$ were in public hospitals. In some regions there were no private hospitals, which were funded by the NHS (Val d'Aosta), while in other regions the percentage was as high as $53 \%$ (Campania) (Table 2).

In 2006, in Italy, the mean length of stay in hospital of elderly patients was 9.4 days. It had been of 9.5 days in 2001 and 10.1 days in 1996. The average stay stretched from 7.7 days in Sicilia to 12.5 in Val d'Aosta (Table 2).

\subsection{Home care and nursing homes}

In Italy, the elderly receiving any kind of home care services (from daily home care to occasional home services) were 165,604 in $1996,214,515$ in 2001, and 351,398 in 2006. In the same period the elderly population in Italy increased from 9,602,352 in 1996 to $11,592,966$ in 2006 . Therefore, the percentage of elderly people being given some kind of home care was 17.2/1000 in 1996, 21.0 in 2001 , and 30.3 in 2006. Table 2 lists the home care coverage in the Italian regions in 2006.

The Institutionalization Rate (elderly admitted in Nursing Homes/elderly population) in 2006 was 19.9/1000, ranging from 4.73 (Basilicata) to 49.93 (PA Trento) (Table 2).

\subsection{Univariate and multivariate analyses}

The Pearson's correlation coefficients between hospitalization rate in the different regions, and bed rates, percentage of private vs. public beds, proportion of day care beds, nursing home bed rates, rate of elderly on home care, length of stay, or the percentage of elderly out of the total population. The main significant correlation was with the bed rates $(r=0.486 ; p=0.022)$ (Table 3$)$.

The applied linear regression models incorporated one dependent variable, hospitalization rates in 2006 in the different regions, and several possible independent variables: bed rates, percentage of private vs. public beds, proportion of day-care beds, nursing home bed rates, rate of elderly on home care, and length of stay (Table 3 ). Hypothesis testing with this general linear model was performed in two ways with the same design matrix: as several independent univariate tests and as multivariate analysis.

At univariate testing, the matrices that related in a statistically significant way with the different hospitalization rates were length of stay $(\beta=-0.47 ; p=0.027)$ and bed rate $(\beta=0.54 ; p=0.009)$. No other variable was statistically significant (Table 3 ).

The multivariate model was statistically significant in explaining the variations in hospitalization rates among the different regions ( $F$ : $5.68 ; p=0.004 ; R^{2}=0.77$ ). The variables, which were more strongly linked to such variations, were the bed rate ( $\beta=0.67 ; p=0.004)$, the percentage of elderly in the population $(\beta=-0.61 ; p=0.01)$, the average length of stay of $\geq 65$ patients $(\beta=-0.77 ; p=0.03)$, and the proportion of private beds out of the total number of acute beds $(\beta=-0.57 ; p=0.02)$. The scatter plot of the multivariate linear regression is shown in Fig. 1, with the different Italian regions as plotted points.

\section{Discussion}

Hospital discharge data can be valuable sources for epidemiological information. We used here the Health Search Databases (HSDs) of all Italian regions to evaluate the variations of hospitalization rates in the elderly population during a ten-yearlong period (1996-2006).

In today's Western healthcare systems, budget cuts, staff shortages, and resource limitations are serious concerns. Therefore, pressure has been put especially on acute hospitals to reduce the number of beds and to decrease the length of stay of the patients. Also Italy has moved in this direction: Our data show that the bed rate from 2001 to 2006 decreased significantly all over Italy. In fact, the overall bed rate of Italy both in 2001 and 2006 is lower than the OECD average (OECD Health Data, 2009). We could 
Table 3

Determinants of elderly acute hospitalization rate: Pearson correlation, univariate and multivariate regression models.

\begin{tabular}{|c|c|c|c|c|c|c|c|c|}
\hline & \multicolumn{8}{|c|}{ Independent variables } \\
\hline & & $\begin{array}{l}\geq 65 \text { average } \\
\text { length of stay }\end{array}$ & $\begin{array}{l}\text { Beds per } 1000 \\
\text { inhabitants }\end{array}$ & $\begin{array}{l}\text { Percentage of private } \\
\text { beds out of the total } \\
\text { number of beds } \\
\text { (private and public) }\end{array}$ & $\begin{array}{l}\geq 65 \text { outpatients } \\
\text { admissions/total } \\
\geq 65 \text { admission rate }\end{array}$ & $\begin{array}{l}\text { Institutionalization } \\
\text { rate }\end{array}$ & $\begin{array}{l}\text { Number of } \\
\geq 65 \text { home } \\
\text { care patients per } \\
1000 \geq 65 \\
\text { inhabitants }\end{array}$ & $\begin{array}{l}\text { Percentage of } \\
\text { elderly out of the } \\
\text { total population }\end{array}$ \\
\hline \multirow[t]{2}{*}{ Correlation } & $r$ & 0.412 & 0.486 & 0.231 & 0.152 & 0.240 & 0.444 & -0.113 \\
\hline & $p$ & 0.063 & 0.022 & 0.315 & 0.500 & 0.307 & 0.044 & 0.624 \\
\hline \multirow{3}{*}{$\begin{array}{l}\text { Univariate Linear } \\
\text { Regression }\end{array}$} & t-test & $\beta=-0.47$ & $\beta=0.54$ & $\beta=0.14$ & $\beta=-0.35$ & $\beta=-0.46$ & $\beta=0.12$ & $\beta=-0.39$ \\
\hline & & $R^{2}=0.18$ & $R^{2}=0.26$ & $R^{2}=0.03$ & $R^{2}=0.08$ & $R^{2}=0.21$ & $R^{2}=0.04$ & $R^{2}=0.11$ \\
\hline & & $p=0.027$ & $p=0.009$ & NS & NS & NS & NS & NS \\
\hline \multirow{3}{*}{$\begin{array}{l}\text { Multivariate } \\
\text { linear } \\
\text { regression }\end{array}$} & $\begin{array}{l}\text { Fisher } \\
\text { exact test }\end{array}$ & $\beta=-0.77$ & $\beta=0.67$ & $\beta=-0.57$ & $\beta=-0.18$ & $\beta=0.26$ & $\beta=-0.14$ & $\beta=-0.61$ \\
\hline & & $p=0.034$ & $p=0.004$ & $p=0.022$ & NS & NS & NS & $p=0.010$ \\
\hline & & \multicolumn{7}{|c|}{$R^{2}=0.77 F: 5.68 ; p=0.004$} \\
\hline
\end{tabular}

Dependent variable is the Hospitalization rate of the $\geq 65$ (per $1000 \geq 65$ inhabitants).

$r$ : Pearson product-moment correlation coefficient.

$\beta$ : $\beta$-Coefficient.

$R^{2}$ : Coefficient of determination.

NS: Non-significant $p$-value.

also observe that bed rates in Italy differ significantly from region to region, ranging from 3.6/1000 in Campania to 5.8/1000 in Lazio.

At the same time, in the period 1996-2006, we observed also a $20 \%$ decrease in hospitalization rates among the elderly (from $324.2 / 1000$ to $258.7 / 1000$ ). The reduction in the period 2001-2006 was twice as strong as the reduction in the period 1996-2001 (14.3\% vs. 6.8\%), indicating an acceleration in the decline of hospitalization rates. The reduction concerned both the "youngold" (65-74 y) and the "old-old" (older than $75 \mathrm{y}$ ) in the same proportion ( $-15.7 \%$ vs. $-14.9 \%$ ). Interestingly, a similar decrease in hospitalizations $(-16.1 \%)$ was observed also among the adults (15-64 y). However, the decline in hospitalization rates was not homogeneous among the Italian regions, ranging from 4 to $23 \%$. In Italy, health care is carried out at regional level, and such huge differences in hospitalization reductions indicate a non uniformity in health planning among the regions, as well as different approaches in budget cuts. Discrepancies throughout the Italian territory are highlighted also by the different proportions of private acute hospitals funded by the NHS. In Italy the public system makes use of both public and private hospitals, whose expenses are nevertheless covered by public money. Overall, about $25 \%$ of public funds allocated for acute care go to private hospitals, albeit with huge differences between areas. We could observe that there are regions, which do not use private hospitals at all (Val D'Aosta) or in

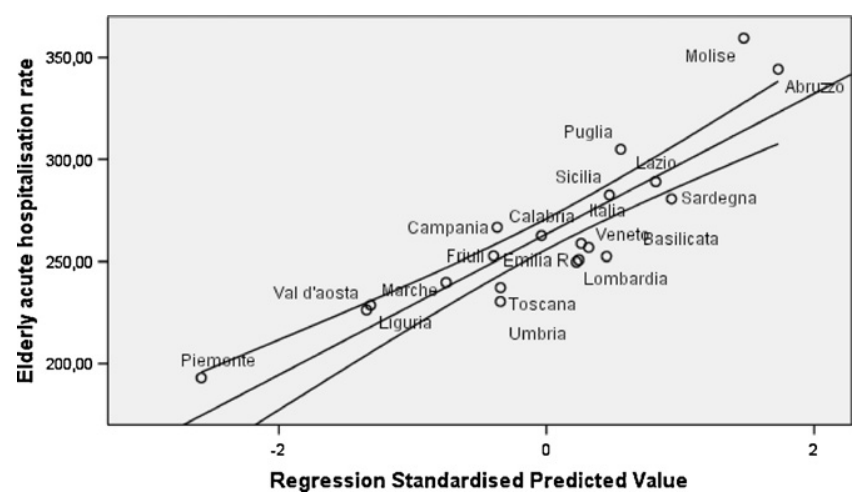

Fig. 1. Scatterplot of the multivariate linear regression, with the different Italian regions as plotted points. The central line is the linear regression model fit to the data. Lateral lines represent the 95\% confidence intervals. Dependent and independent variables of the model are described in Table 3. a limited way (e.g. Veneto, Liguria, Umbria, Basilicata), and regions that use private structures extensively (e.g. Campania, Calabria, Lazio).

The average hospital of stay of the elderly patients was almost unchanged in the examined period ( 10.1 days vs. 9.4 days); this is probably due to the fact that a strong reduction in length of stay had already taken place during the nineties (SDO, 2011), in relation to the introduction of the DRG system in Italy. The reduction in length of stay of elderly patients, at least in the present situation, has apparently reached a plateau. Further reductions can be probably envisaged only in connection with specific outpatient interventions, which have not yet been extensively developed in the country. Furthermore, our data indicate that regions with the shortest hospital stay, like Campania, Calabria or Sicilia, are also the regions with the lowest percentage of elderly receiving home care services and with the lowest nursing home bed rates. This is at odds with the experiences of other countries, where it has been shown that home care has an effect on reducing hospital stay (Hughes et al., 1997).

Our data, while indicating a clear reduction of hospital admission rates of older persons, do not show a relation with an increased offer of home care or of nursing home services. Actually, the percentage of elderly people receiving some kind of home care, which was $1.7 \%$ in 1996 , became $3 \%$ in 2006 . Notwithstanding this increase, the percentage of aged people receiving home care services is still very low, if compared with other European countries (Stuart and Weinrich, 2001). Moreover, the univariate and multivariate linear regression models do not show a correlation between reductions in admission rates and rates of elderly on home care or in institutions. Our data seem to point essentially to a stronger correlation between lower admission rates and lower bed rates, longer length of stay, higher proportion of private acute beds, and higher number of elderly. In other words, it seems that the main determinant of lower elderly hospitalization is not the provision of alternative services, but acute bed availability. Nevertheless, a coefficient of determination of about 0.8 at the multivariate analysis indicates that a few other factors not included in this model might play a role as well.

To manage the demand of care by using the tool of changing the provision of services is quite frequent in health policies. For example, in Australia in the nineties, the increased supply of "same day Beds" led to a decrease of inpatients care among the 65-74 old patients (but not among the older ones) (Gray et al., 2004; Mackay 
and Millard, 2005). In this case the final outcome was, therefore, not a generalized reduction of hospitalizations, as we have observed in Italy. It is likely that in Australia the offer of old and new services has been better distributed than in Italy.

To reduce the number of hospital beds is a common policy in several Western countries, but, usually, it is accompanied by the offer of alternative services (Victor, 2001; Okamoto, 2011); in Japan, the forecast massive reduction of inpatient beds dedicated to "long term patients", came with a massive increase of nursing homes, so to offer alternative services to the people with chronic diseases. But, again, according to our results, this does not seems to be the case in Italy.

Also in Europe, the reduction of hospital admissions is an ongoing process happening in the framework of already existing out-patients and non-hospital care services. Even comparing with countries of Southern Europe, where out-of-hospital care is less developed, like Spain, Greece, or Portugal, we observe that Italy has the largest reduction of inpatient beds rate (OECD, 2011) And this, notwithstanding that the offer of out-of-hospital care services in Italy is among the lowest in Europe (Huber, 2011).

On the contrary, in several countries (Experton et al., 1997; Stuart and Weinrich, 2001) a decreased access to acute hospitals and shorter length of stay has kept up with a dramatic growth of home care. In such a transition of health care systems, the posthospitalization period is seen as a high-risk time, since some studies have found that the elderly who are discharged home earlier are often discharged sicker and more dependent (Mahoney et al., 2000; Grimmer et al., 2004; Shepperd et al., 2004). Some studies indicate that about $20 \%$ of the hospitalizations of elderly are complicated by postdischarge adverse events (Forster et al., 2004). Therefore, the successful discharge of older patient requires an uninterrupted and adequate help at home, as well as integrated services.

This analysis arises the question on the reasons of this drop in hospitalization rates of older people. It might be that, globally, the health status of the elderly has improved, leading to fewer hospitalizations, or that, before, many hospitalizations were inappropriate. But, the diminished rates could also be a sign of unmet needs and a lack of effective planning (Curran et al., 1992; Williams et al., 1992; Closs and Tierney, 1993), which should include also a wider strategy of continuity of care (Jack et al., 2009b). Continuity of care is recognized to be essential, particularly in chronic or complex diseases that require the involvement of several providers in different settings (Damiani et al., 2009). It is widely recognized that continuity of care should be a major concern of health care systems (van Walraven et al., 2004), to guarantee better outcomes and higher health-care quality (Donaldson, 2001). It has been highlighted that older patients are often left unprepared at discharge from hospital, and many are not aware of their discharge medications and cannot recall their main diagnoses (Makaryus and Friedman, 2005). Furthermore, no preventive chronic care management programs, which have been shown to be effective in reducing hospital admission rates among the elderly (Hamar et al., 2011), have been widely developed in Italy.

It should be mentioned that Italy identified the need of continuity of care strategies already in 1992, however, with few exceptions (Damiani et al., 2009), it has not been extensively implemented. Therefore, it is plausible that the needs of the older patients have been actually shifted toward family and informal caregivers, especially in Southern Italy, with the possible consequence, as it has been widely shown in other countries, of an overreliance on informal support (Congdon, 1990), and lack of awareness to the individual needs of the most vulnerable (Klop et al., 1991). It is likely that Italian families have served as safety nets for many of these patients, as it has occurred also in the USA
(Experton et al., 1997). In fact, during the examined ten-year period, the out of pocket payment per capita (in US\$ PPP) increased in Italy from 428 to 533US\$ (OECD Health Data, 2009), and the number of domestic helper, employed privately by the families, has dramatically increased (Ministero del Lavoro, 2010). Private domestic helper took care in Italy in 2009 of $6.6 \%$ of the over-65, with a total cost for the families of more than 9 billion Euros (Ministero del Lavoro, 2010). Families are, therefore, more and more expected to bridge the gap from hospital to home with the consequent risk of unmet needs. This could mean that the decline in functional ability experienced by the elderly is simply shifted toward the families, and not toward nursing homes or home-care services, possibly leading to a significant increase in care being provided by family caregivers, mainly women, possibly leading the ones who work to leave the labor force to provide more informal care (Byung-Kwang et al., 2004). In addition, relying mainly on informal family support means also that, in case of lack of a family - situation that is more and more common in Italy - health outcomes might be seriously affected (McClaran et al., 1996).

The main limitation of this study is due to the fact that in the HSDs there is no information on the health status of the discharged person in terms of functional status and socio-economic resources, which are known to be among the main determinants of the need of long-term care. Moreover, no information at national level about the capacity of out-of-hospital services to absorb the demand of care (e.g. the waiting-time between the request of care and the provision of services) is available in Italy.

Therefore, our conclusions should be confirmed by future studies focussing especially on aspects like disability level and/or functional ability, as well as the diagnoses of the hospitalized, compared to the non-hospitalized elderly.

Nevertheless, to our knowledge, this is the first study in Italy, which, despite the lack of available data, seeks to analyze the relation between changes in hospitalization rates and availability of alternative services for the elderly. These results allow to draw some preliminary conclusions on the presence of unmet needs in Italy. In fact, the analysis of such a large database can give important indications on possible strength and weaknesses of health care systems, calling health care administrators to make their data samples, created for DRG calculation, widely accessible to researchers.

In conclusion, in Italy we observed a reduction in hospitalization rates, which has not been counterweighted by an increased offer of home care and/or nursing home services, but was mainly linked to a simple decrease in the supply of acute beds. The supply of services for the elderly should therefore be seen as a central economic and public health issue for the Italian health care system. Future studies should be directed at evaluating the health impact on older people that these changes might have caused.

\section{Certification of authorship}

All authors gave substantial contributions to (1) conception and design or analysis and interpretation of data, and (2) drafting the article or revising it critically for important intellectual content, and on (3) final approval of the version to be published.

\section{Funding}

None.

\section{Conflict of interest statement}

None declared. 


\section{Ethical approval}

Not required.

\section{Acknowledgements}

The authors acknowledge the Italian Ministry of Health, General Direction of Health Planning for the Kind Collaboration in providing data about the DRGs of year 2001.

\section{References}

Audit Commission, 1997. The Coming of Age: Improving Care Services for Older People. Audit Commission, London.

Byung-Kwang, Y., Bhattacharya, J., McDonald, K.M., Garber, A.M., 2004. Impacts of informal caregiver availability on long-term care expenditures in OECD countries. Health Serv. Res. 39, 1971-1992.

Closs, S.J., Tierney, A.J., 1993. The complexities of using a structure, process and outcome framework: the case of an evaluation of discharge planning for elderly patients. J. Adv. Nurs. 18, 1279-1287.

Coast, J., Inglis, A., Frankel, S., 1996. Alternatives to hospital care: what are they and who should decide. BMJ 312, 162-166.

Coast, J., Richards, S.H., Peters, T.J., Gunnell, D.J., Darlow, M.-A., Pounsford, J., 1998. Hospital at home or acute hospital care? A cost minimisation analysis. BMJ 316 , 1802-1806.

Congdon, J.G., 1990. Management the incongruities: an analysis of hospital discharge of the elderly. Communicating Nursing Research, Nursing ResearchTranscending the 20th Century, 23. pp. 9-17.

Curran, P., Gilmore, D.H., Beringer, T.R.O., 1992. Communication of discharge information for elderly patients in hospital. Ulster Med. J. 61, 56-58.

Dainty, P., Elizabeth, J., 2009. Timely discharge of older patients from hospital: improving the process. Clin. Med. 9, 311-314.

Damiani, G., Federico, B., Venditti, A., Sicuro, L., Rinaldi, S., Cirio, F., Pregno, C., Ricciardi, W., 2009. Hospital discharge planning and continuity of care for aged people in an Italian local health unit: does the care-home model reduce hospital readmission and mortality rates? BMC Health Serv. Res. 9, 22

Department of Health [London], 2002. NHS Performance Indicators. Department of Health (Crown Copyright), London.

Donaldson, M.S., 2001. Continuity of care: a reconceptualization. Med. Care Res. Rev. 58, 255-290.

Experton, B.L., Branch, L.G., Ozminkowski, R.J., Mellon-Lacey, D.M., 1997. The impact of payor/provider type on heath care use and expenditures among the frail elderly. Am. J. Public Health 87, 210-216.

Forster, A.J., Clark, H.D., Menard, A., Dupuis, N., Chernish, R., Chandok, N., Khan, A., van Walraven, C., 2004. Adverse events among medical patients after discharge from hospital. Can. Med. Assoc. J. 170, 345-349.

France, G., Taroni, F., Donatini, A., 2005. The Italian health-care system. Health Econ. 14, S187-S202.

Graves, E.J., 1995. National center for health statistics, national hospital discharge survey: annual summary 1993. Vital Health Stat. 13 121, 1-63.

Gray, L.C., Yeo, M.A., Duckett, S.J., 2004. Trends in the use of hospital beds by older people in Australia: 1993-2002. Med. J. Aust. 181, 478-481.

Grimmer, K., Moss, J., Falco, J., 2004. Becoming a carer for an elderly person after discharge from an acute hospital admission. Internet J. Allied Health Sci. Pract. 2 .

Hamar, B., Wells, A., Gandy, W., Bradley, C., Coberley, C., Pope, J.E., Rula, E.Y., 2011. The impact of proactive chronic care management on hospital admissions in a German senior population. Popul. Health Manage. 14 (Suppl. 1), S29-S33.

Huber, M., 2011. Long-term care for older people: The future of Social Services of General Interest in the European Union: Discussion Paper. http://www.peerreview-social-inclusion.eu/peer-reviews/2007/the-future-of-social-servicesof-general-interest/pr_be_07_discussion-paper (accessed 22.07.11).

Hughes, S.L., Ulasevich, A., Weave, F.M., Henderson, F.M., Manheim, L., Kubal, J.D., Bonarigo, F., 1997. Impact of home care on hospital days: a meta analysis. Health Serv. Res. 32, 415-432.

Istituto Nazionale di Statistica (ISTAT). http://www.demo.istat.it (accessed 31.07.10).
Istituto Nazionale di Statistica (ISTAT), 2003. [National Institute of Statistics], Sanità e Salute. In: Annuario Statistico Italiano, Rome, pp. 64-68.

Jack, B.W., Chetty, V.K., Anthony, D., Greenwald, J.L., Sanchez, G.M., Johnson, A.E., Forsythe, S.R., O’Donnel, J.K., Paasche-Orlow, M.K., Manasseh, C., Martin, S. Culpepper, L., 2009a. A reengineered hospital discharge program to decrease rehospitalisation: a randomized trial. Ann. Intern. Med. 150, 178-187.

Jack, B.W., Chetty, V.K., Anthony, D., Greenwald, J.L., Sanchez, G.M., Johnson, A.E., Forsythe, S.R., O’Donnel, J.K., Paasche-Orlow, M.K., Manasseh, C., Martin, S. Culpepper, L., 2009b. Reengineered hospital discharge program to decrease rehospitalisation: a randomized trial. Ann. Intern. Med. 150, 178-187.

Jommi, C., Cantu', E., Anessi-Pessina, E., 2001. New funding arrangements in the Italian National Health Service. Int. J. Health Plann. Manage. 16, 347-368.

Klop, R., van Wijmen, F.C.B., Philipsen, H., 1991. Patients' rights and the admission and discharge process. J. Adv. Nurs. 16, 408-412.

Liotta, G., Brenna, A., 2007. Evolution of the in-patient hospital expenditure for the elderly in Italy: 1996-2001 comparison. Arch. Gerontol. Geriat. 45, 169-177.

Mackay, M., Millard, P., 2005. Trends in the use of hospital beds by older people in Australia: 1993-2002. Med. J. Aust. 182, 252-253.

Mahoney, J.E., Palta, M., Johnson, J., Jalaluddin, M., Gray, S., Park, S., Sager, M., 2000 Temporal association between hospitalisation and rate of falls after discharge. Arch. Intern. Med. 160, 2788-2795.

Makaryus, A.N., Friedman, E.A., 2005. Patients' understanding of their treatment plans and diagnosis at discharge. Mayo Clin. Proc. 80, 991-994.

McClaran, J., Berglas, R.T., Duarte Franco, E., 1996. Long hospital stays and need for alternate level of care at discharge. Does family make a difference for elderly patients? Can. Fam. Physician 42, 449-461.

Merriman, M.L., 2008. Pre-hospital discharge planning: empowering elderly patients through choice. Crit. Care Nurs. Q. 31, 52-58.

Ministero del Lavoro e delle Politiche Sociali [Italian Ministry of Work and Welfare]. Rapporto sulla non-autosufficienza in Italia-2010 [Report on non-self-sufficiency in Italy - 2010]. Rome, July 2010. http://www.lavoro.gov.it/NR/rdonlyres/ 9B939247-1A95-468A-9A54-6E58BE0DD85C/0/210710rapportosullanonautosufficienza.pdf (accessed 31.07.10).

Oddone, E.Z., Weinberger, M., Horner, M., Mengel, C., Goldstein, F., Ginier, P., Smith, D., Huey, J., Farber, N.J., Asch, D.A., Loo, L., Mack, E., Hurder, A.G., Henderson, W., Feussner, J.R., 1996. Classifying general medicine readmissions: are they preventable? J. Gen. Intern. Med. 11, 579-605.

OECD health statistics, 2011. http://www.oecd.org/dataoecd/52/42/ 48304068.xls\#'Hospital beds'!A1 (accessed 22.07.11).

OECD Health Data, 2009. http://www.oecd.org/dataoecd/45/52/43216313.pdf (accessed 31.07.10).

Okamoto, E., 2011. Japan quest for reduction of LTC hospital beds. http://apha.confex.com/apha/135am/recordingredirect.cgi/id/17921 (accessed 22.07.11).

Preyde, M. Macaulay, C., Dingwall, T., 2009. Discharge planning from hospital to home for elderly patients: a meta-analysis. J. Evid. Based Soc. Work 6, 198-216.

Reinhardt, U., 1996. Spending more through 'cost control': our obsessive quest to gut the hospital. Health Affairs 2, 145-154.

Rapporto sull'attività dei ricoveri ospedalieri in Italia (SDO) [Report on hospital discharges in Italy], anno 1996 - Rapporto SDO 1996. http://www.salute.gov.it/ ricoveriOspedalieri/archivioDocumentiRicoveriOspedalieri.jsp?lingua=italiano\&menu=documenti (accessed 31.07.10)

Seshamani, M., Gray, A., 2002. The impact of ageing on expenditures in the national health service. Age Ageing 31, 287-294.

Shepperd, S., Parkes, J., McClaran, J., Phillips, C., 2004. Discharge planning from hospital to home. Cochrane Database Syst. Rev. 1, 1-38.

Shepperd, S., Doll, H., Broad, J., Gladman, J., Iliffe, S., Langhorne, P., Richards, S., Martin, F., Harris, R., 2009. Early discharge hospital at home. Cochrane Database Syst. Rev. 21, CD000356.

Stuart, M., Weinrich, M., 2001. Home- and community-based long-term care: lessons from Denmark. Gerontologist 41, 474-480.

van Walraven, C., Mamdani, M., Fang, J., Austin, P.C., 2004. Continuity of care and patient outcomes after hospital discharge. J. Gen. Intern. Med. 19, 624-631.

Victor, B., 2001. California Acute Care Hospital Beds on the Decline. http://www.articlesbase.com/mental-health-articles/california-acute-care-hospital-beds-onthe-decline-2902057.html (accessed 22.07.11).

Williams, E.I., Greenwell, J., Groom, L.M., 1992. The care of people over 75 years old after discharge from hospital an evaluation of timetabled visiting by health visitor assistants. J. Public Health Med. 14, 138-144. 